\title{
Postinfarction Cardiac Remodeling Proceeds Normally in Granulocyte Colony-Stimulating Factor Knockout Mice
}

Kentaro Morishita, ${ }^{* \dagger}$ Genzou Takemura, ${ }^{\dagger \dagger}$ Akiko Tsujimoto, ${ }^{\dagger}$ Hiromitsu Kanamori, ${ }^{\dagger}$ Hideshi Okada, ${ }^{* \dagger}$ Mitsuhiro Chousa, Seiko Ushimaru, ${ }^{\S}$ Atsushi Mikami, ${ }^{\dagger}$ Itta Kawamura, ${ }^{\dagger}$ Toshiaki Takeyama, ${ }^{\dagger}$ Tomonori Kawaguchi, ${ }^{{ }^{\dagger}}$ Takatomo Watanabe, ${ }^{*}$ Kazuko Goto, ${ }^{\dagger}$ Megumi Morishita, ${ }^{\dagger}$ Hiroaki Ushikoshi, ${ }^{* \dagger}$ Masanori Kawasaki, ${ }^{\dagger}$ Shinji Ogura, ${ }^{*}$ and Shinya Minatoguchi

From the Departments of Emergency and Disaster Medicine, ${ }^{*}$ Cardiology, ${ }^{\dagger}$ and Informative Clinical Medicine,${ }^{\S}$ Gifu University Graduate School of Medicine, Gifu; and the Department of Internal Medicine, ${ }^{\ddagger}$ Asahi University School of Dentistry, Mizuho, Japan

Accepted for publication

March 24, 2015.

Address correspondence to Genzou Takemura, M.D., Ph.D., Department of Internal Medicine, Asahi University School of Dentistry, 1851 Hozumi, Mizuho 501-0296, Japan. E-mail: gt@dent.asahiu.ac.jp.

\begin{abstract}
Treatment with granulocyte colony-stimulating factor (G-CSF) reportedly mitigates postinfarction cardiac remodeling and dysfunction. We herein examined the effects of G-CSF knockout (G-CSF-KO) on the postinfarction remodeling process in the hearts of mice. Unexpectedly, the acute infarct size 24 hours after ligation was similar in the two groups. At the chronic stage (4 weeks later), there was no difference in the left ventricular dimension, left ventricular function, or histological findings, including vascular density, between the two groups. In addition, expression of vascular endothelial growth factor (VEGF) was markedly up-regulated in hearts from G-CSF-KO mice, compared with wild-type mice. Microarray failed in detecting up-regulation of VEGF mRNA, whereas G-CSF administration significantly decreased myocardial VEGF expression in mice, indicating that G-CSF post-transcriptionally downregulates VEGF expression. When G-CSF-KO mice were treated with an anti-VEGF antibody (bevacizumab), cardiac remodeling was significantly aggravated, with thinning of the infarct wall and reduction of the cellular component, including blood vessels. In the granulation tissue of bevacizumab-treated hearts 4 days after infarction, vascular development was scarce, with reduced cell proliferation and increased apoptosis, which likely contributed to the infarct wall thinning and the resultant increase in wall stress and cardiac remodeling at the chronic stage. In conclusion, overexpression of VEGF may compensate for the G-CSF deficit through preservation of cellular components, including blood vessels, in the postinfarction heart. (Am J Pathol 2015, 185: 1899-1911; http://dx.doi.org/10.1016/j.ajpath.2015.03.018)
\end{abstract}

Large myocardial infarctions (MIs) cause severe chronic heart failure with unfavorable remodeling of the left ventricle, characterized by ventricular dilatation and diminished cardiac performance. ${ }^{1}$ The size of the acute infarction, which can be determined within several hours after an attack, is the most critical determinant of the subsequent heart failure. ${ }^{2}$ Early postinfarction changes in the architecture of the left ventricle are adaptive responses to the acute loss of functional myocardium and initially preserve cardiac performance. However, once these processes develop after a large MI, the infarcted heart progressively dilates, accelerating the deterioration of ventricular function and eventually leading to heart failure.

Evidence from several studies suggests granulocyte colony-stimulating factor (G-CSF), a hematopoietic cytokine, can alleviate postinfarction left ventricular (LV) remodeling and heart failure. ${ }^{3-7}$ Various mechanisms have been proposed for the beneficial effects of G-CSF on the infarcted heart, including regeneration of myocardium, ${ }^{3,4}$ acceleration of the healing process, ${ }^{5}$ direct protection of cardiomyocytes from apoptosis, ${ }^{6}$ protection of salvaged cardiomyocytes, and reduction of myocardial fibrosis. ${ }^{7}$ G-CSF knockout (G-CSF-KO) mice show chronic neutropenia, granulocyte and macrophage progenitor cell deficiencies, and impaired neutrophil mobilization. ${ }^{8}$ Although approximately $50 \%$ of $\mathrm{G}-\mathrm{CSF}-\mathrm{KO}$ mice die in utero, the surviving mice grow to

Supported in part by Gifu University research grants (S.M.).

Disclosures: None declared. 
adulthood. ${ }^{8}$ In that context, we hypothesized that postinfarction LV remodeling would be exacerbated in G-CSFKO mice, compared with the wild-type (WT) mice. To test that idea, we induced MI in G-CSF-KO and WT mice and observed them until the chronic stage (4 weeks after infarction). Unexpectedly, we noted no difference in the postinfarction process between the mice. This prompted us to investigate the underlying molecular mechanisms that could explain this unexpected outcome.

\section{Materials and Methods}

\section{Animals and Experimental Protocols}

This study conforms with the Guide for the Care and Use of Laboratory Animals ${ }^{9}$ and was approved by the Institutional Animal Research Committee of Gifu University (Gifu, Japan). Male G-CSF-deficient mice (B6; 129P2-Csf $3^{\text {tmlArd } / J) ~ w e r e ~}$ purchased from Jackson Laboratory (Bar Harbor, ME) and bred as described previously. ${ }^{8}$ G-CSF genotypes were routinely determined by PCR analysis of tail DNA before use. The PCR primers used were as follows: i) $5^{\prime}$-TCCATGACATCTGTGGCCACCAGA- $3^{\prime}$, corresponding to sequences $5^{\prime}$ of the Asp700 site in the G-CSF promoter; ii) $5^{\prime}$-CGGCCTCTCGTCCTGACCATAGTG-3' ${ }^{\prime}$, corresponding to sequences in exon 2 of the G-CSF gene deleted by targeted construct integration (bp 152 to 175 of the genomic G-CSF sequence); and iii) 5'-CTGCAAGGCGATTAAGTTGGGTAA-3', corresponding to the $5^{\prime}$ region of the Escherichia coli lac-z gene. In the PCR, primers $\mathrm{i}$ and ii amplify a 1.4-kb product from WT template DNA, whereas primers i and iii amplify a $1.3-\mathrm{kb}$ product from DNA containing a correctly integrated targeted construct. The genotypes were designated as WT $\left(\mathrm{G}-\mathrm{CSF}^{+/+}\right)$, heterozygous $\left(\mathrm{G}-\mathrm{CSF}^{+/-}\right)$, and homozygous G-CSF-KO (G-CSF $\left.{ }^{-I-}\right)$. It is known that the peripheral blood neutrophil counts in G-CSF-KO mice are reduced by $70 \%$ to $80 \%$ compared with WT mice, and there is a 50\% reduction in granulocytes, macrophages, and blast progenitor cells in the bone marrow of G-CSF$\mathrm{KO}$ mice and impaired resistance to infection with Listeria monocytogenes. ${ }^{8}$

G-CSF-KO and WT mice (10 to 12 weeks old) were initially anesthetized with $2 \%$ halothane in a mixture of $\mathrm{N}_{2} \mathrm{O}$ and $\mathrm{O}_{2}(0.5 \mathrm{~L} /$ minute each $)$ via a nasal mask and then intubated with a 20 gauge i.v. catheter and ventilated with $0.5 \%$ halothane in a mixture of $\mathrm{N}_{2} \mathrm{O}(0.1 \mathrm{~L} /$ minute $)$ and $\mathrm{O}_{2}$ $(0.5 \mathrm{~L} /$ minute) using a rodent ventilator. MI was induced by ligating the left coronary artery, as described previously (WT, $n=92$; KO, $n=132$ ). ${ }^{10,11}$ Sham animals underwent the same surgical procedures, except the left coronary artery was not occluded (WT, $n=20$; KO, $n=20$ ). The surviving mice were sacrificed with an overdose of pentobarbital $(50 \mathrm{mg} / \mathrm{kg}) 1$ day (acute stage: WT, $n=26$; $\mathrm{KO}, n=26$ ), 4 days (subacute stage: WT, $n=36$; KO, $n=76$ ), or 4 weeks (chronic stage: WT, $n=30$; KO, $n=30)$ after the surgery.
In another set of experiments, mice surviving 1 day after the surgery $(n=24)$ were assigned to one of two groups after echocardiographic examination: a saline-treated group (control: $\mathrm{WT}, n=6 ; \mathrm{KO}, n=6$ ) or a $0.36 \mathrm{mg} / \mathrm{kg}$ per day bevacizumabtreated group (Sigma-Aldrich, St. Louis, MO: WT, $n=6 ; \mathrm{KO}$, $n=6$ ). Bevacizumab is a humanized monoclonal antibody that inhibits vascular endothelial growth factor A (VEGF-A), a chemical signal that stimulates angiogenesis in a variety of diseases, especially cancer. ${ }^{12,13}$ It is approved for the treatment of cancers, including colorectal, lung, breast, glioblastoma, kidney, and ovarian. Saline and bevacizumab were continuously administered using s.c. embedded osmotic minipumps (ALZET osmotic mini-pump 1002; DURECT, Cupertino, CA) from day 1 after infarction until the mice were sacrificed.

\section{Blood Cell Counts and Determination of G-CSF in Serum}

Serum G-CSF concentrations were determined in WT and G-CSF-KO mice ( $n=3$ each) using an enzyme-linked immunosorbent assay kit (R\&D Systems, Minneapolis, $\mathrm{MN})$. Peripheral granulocytes and monocytes were counted at the indicated timings in each group $(n=3)$ using the standard method.

\section{Measurement of Serum Troponin I Levels}

Serum concentrations of cardiac troponin I were measured 1 day after coronary artery ligation ( $n=6$ from each group) using an enzyme immunoassay kit (Access AccuTnI; Beckman Coulter, Brea, CA).

\section{Physiological Studies}

Echocardiography and cardiac catheterization were performed as previously described. ${ }^{14}$ Because of its invasiveness, cardiac catheterization was performed only before sacrifice.

\section{Assessment of AAR and Infarct Size}

In mice with a 1-day-old MI, the ischemic area at risk (AAR) and the infarct area were measured using the previously reported method, with some modification. ${ }^{15}$ Briefly, the animals were anesthetized and intubated, and the chest was opened. The ascending aorta was cannulated and perfused with saline to wash out the blood. To demarcate the AAR, $1 \%$ Evans Blue Dye (Wako Pure Chemical, Osaka, Japan) was infused into the aorta and coronary arteries. The hearts were then excised, and the ventricles were sliced into cross sections ( $1 \mathrm{~mm}$ thick). The sections were then incubated with a 1\% 2,3,5-triphenyltetrazolium chloride solution (Sigma-Aldrich) for 20 minutes at $37^{\circ} \mathrm{C}$. The infarct area (pale), the AAR (not blue), and the total LV area were measured on both sides of each section using Adobe Photoshop version 13.0.6 (Adobe Systems Inc., San Jose, $\mathrm{CA}$ ), and the values obtained were averaged. The percentage infarction area and AAR of each section were then multiplied 
by the weight of the section and totaled across all sections. The infarct size was determined as a percentage of the AAR.

\section{Histology}

Transverse slices of hearts were fixed in $10 \%$ buffered formalin, embedded in paraffin, cut into sections $(4 \mu \mathrm{m}$ thick), and stained with hematoxylin and eosin, Masson's trichrome, or Sirius red F3BA (0.1\% solution in saturated aqueous picric acid; Sigma-Aldrich). Quantitative assessments, including fibrosis area, cardiomyocyte size, infarct size at the subacute (4-day-old infarction) or chronic (4-weekold infarction) stage, and immunopositive cell number, were performed in 20 randomly chosen high-power fields (HPFs; $\times 400$ magnification) in each section using a multipurpose color image processor (Win ROOF; Mitani Co, Tokyo, Japan). Cardiomyocyte size was expressed as the transverse diameter of myocytes cut at the level of the nucleus. Infarct size at the subacute and chronic stages was histologically determined in preparations stained with Masson's trichrome and expressed as the percentage infarct segment in the left ventricle.

\section{Immunohistochemistry}

After deparaffinization, the sections ( $4 \mu \mathrm{m}$ thick) were incubated with a primary antibody against leukocytes (CD45; number 550539; Pharmingen, Franklin Lakes, NJ), endothelial cells (Flk-1; sc-6251; Santa Cruz, Dallas, TX), VEGF (sc-7269; Santa Cruz), macrophages (F4/80; MCA497R; Bio-Rad, Hercules, CA), mast cells (ab2378; Abcam, Hercules, CA), or proliferating cells (Ki-67; M7249; Dako Japan, Cambridge, MA). A Vectastain Elite $\mathrm{ABC}$ system (Vector Laboratories, Burlingame, CA) was then used to immunostain the sections, with diaminobenzidine hydrochloride serving as the chromogen, and the nuclei were counterstained with hematoxylin. The primary antibodies were substituted with the respective control $\mathrm{IgG}$ in the control sections. In situ terminal deoxynucleotidyl transferasemediated dUTP nick-end labeling (TUNEL) assays were performed using an ApopTag kit (Intergene, Purchase, NY), according to the supplier's instructions. Mammary tissue from the mice served as a positive control.

Ki-67-immunolabeled sections stained with Alexa 488 (green; Molecular Probes, Eugene, OR) were double stained with Texas Red-conjugated Lycopersicon Esculentum (Tomato) lectin (Vector Laboratories) to detect the proliferation of vascular endothelial cells. To double stain for TUNEL and lectin, tissue sections were first stained with Fluorescein-FragEL (Oncogene, Cambridge, MA) and then labeled with the Texas Red-conjugated lectin. Ki-67-immunolabeled sections stained with Alexa 488 were double stained with an anti-myoglobin (Dako Japan) antibody, followed by Alexa 568 (red; Molecular Probe), to assess cell proliferation in myoglobin-positive cardiomyocytes and in myoglobin-negative noncardiomyocytes. To double stain for TUNEL and myoglobin, tissue sections were first stained with Fluorescein-FragEL and then labeled with an anti-myoglobin antibody, followed by Alexa 568 . Finally, sections were counterstained with Hoechst 33342 (Sigma-Aldrich) and observed under a confocal microscope (C2; Nicon, Tokyo, Japan).

\section{Mononuclear Cell Isolation and Flow Cytometric Analysis}

Endothelial progenitor cells (EPCs) were counted in the peripheral blood, as previously reported. ${ }^{16}$ After peripheral blood mononuclear cells were isolated using density gradient centrifugation with Ficoll (Immuno-Biological Laboratories, Mountain View, CA), light density mononuclear cells were harvested and washed twice with phosphate-buffered saline. EPCs were defined by positive staining for CD34 and Flk-1 $\left.\left(\mathrm{CD} 34^{+} / \mathrm{Flk}_{-1}\right)^{+}\right), \mathrm{CD} 34$ and $\mathrm{CD} 133\left(\mathrm{CD} 34^{+} / \mathrm{CD} 133^{+}\right)$, or CD34 and Sca- $1\left(\mathrm{CD} 34^{+} / \mathrm{Sca}-1^{+}\right)$. The antibodies against CD34 and Sca-1 were purchased from BD Biosciences (San Jose, CA), and those against CD133 and Flk-1 were from e-Bioscience (San Diego, CA). Fluorescein isothiocyanateconjugated anti-mouse CD4 and anti-rat $\operatorname{IgG} 2$ a antibodies served as controls (BD Pharmingen, San Jose, CA). After incubation, erythrocytes were lysed using fluorescence-activated cell sorting lysing solution. Cells were then washed with phosphate-buffered saline and analyzed using a FACS Caliber (Becton Dickinson, Franklin Lakes, NJ). Each analysis included 100,000 events. Positive control blood samples $(n=3)$ were prepared from WT mice administered G-CSF via s.c. injection at the dose of $100 \mu \mathrm{g} / \mathrm{kg}$ once daily for 5 days. ${ }^{17,18}$

\section{Western Blot Analysis}

Proteins $(20 \mu \mathrm{g})$ extracted from hearts $(n=3$ from each group) were subjected to $10 \%$ or $15 \%$ polyacrylamide gel electrophoresis and then transferred onto polyvinylidene difluoride membranes. The membranes were then probed using primary antibodies against extracellular signalregulated kinase (ERK; number 9102), Akt, STAT3 (number 9132), phosphorylated ERK (p-ERK; number 9101), p-Akt (number 4051), and p-STAT3 (number 9134) (all from Cell Signaling, Beverly, MA), angiopoietin-1 (ab8451; Abcam), hepatocyte growth factor (HGF; MAB294; R\&D Systems), hypoxia-inducible factor-1a (HIF-1 $\alpha$; ab16066; Abcam), insulin-like growth factor-1 (IGF-1; AF791; R\&D Systems), or VEGF (sc-7269; Santa Cruz), after which the blots were visualized using enhanced chemiluminescence (Amersham, Pittsburgh, PA). $\alpha$-Tubulin [analyzed using an antibody from Santa Cruz (sc-5546)] served as the loading control.

\section{Microarray}

Gene expression profiling was performed on cardiac tissue samples $(n=3$ each from WT, KO, and KO with 2 days postinfarction) using Affymetrix GeneChip (Affymetrix, Santa Clara, CA) mouse gene 2.0 ST arrays. RNA extraction, 
A

(kb)

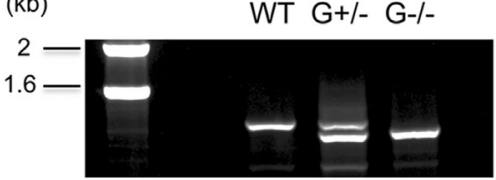

D

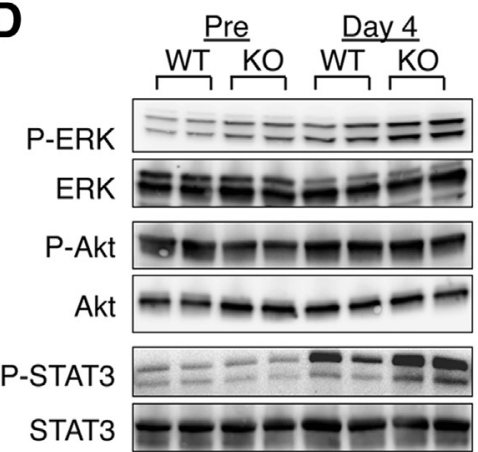

B

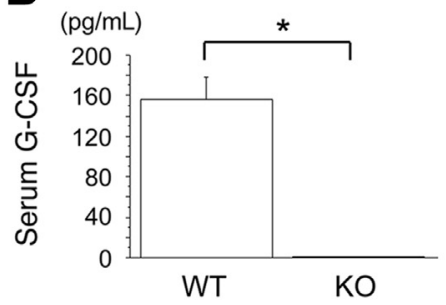

E

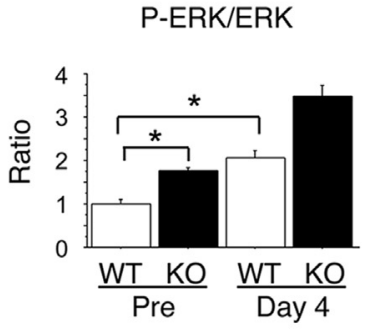

C

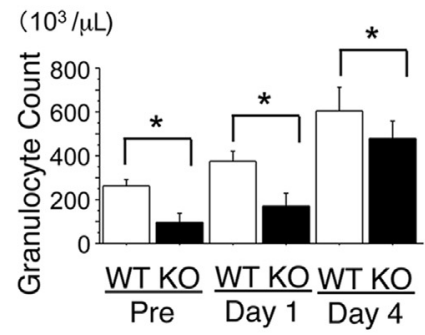

P-Akt/Akt

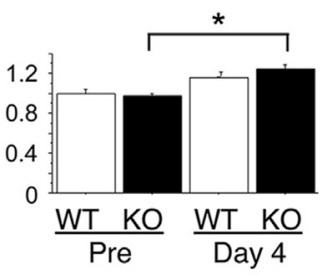

P-STAT3/STAT3

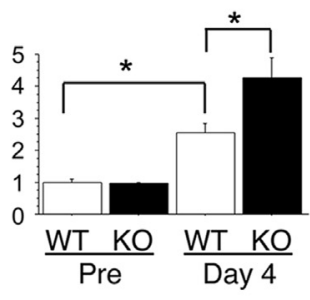

Figure 1 Genotyping, serum granulocyte colony-stimulating factor (G-CSF) concentration, granulocyte counts, and signal transduction downstream of GCSF in G-CSF knockout (G-CSF-KO) mice. A: PCR determination of G-CSF genotype. PCR performed with primers listed in Materials and Methods amplifies products of 1.4 and $1.3 \mathrm{~kb}$ from wild-type (WT; $+/+$ ) and homozygous null $(-/-)$ template DNA, respectively, whereas both products are amplified from heterozygous template DNA (+/-). B: Serum G-CSF concentrations in WT and G-CSF-KO mice. G-CSF was undetectable in G-CSF-KO mice. C: Granulocyte counts in the peripheral blood before the operation and on days 1 and 4 after infarction in WT and G-CSF-KO mice. D: Western blots for Akt, ERK, and STAT3 and their phosphorylated forms. E: Densitometry of Western blots in D. ${ }^{*} P<0.05 . n=6$ each (B, WT and K0 mice); $n=3$ each (C, WT and K0 mice).

generation of sense DNA targets, hybridization, wash, scan, and data analysis were performed at Filgen Biosciences \& Nanosciences (Nagoya, Japan).

\section{Statistical Analysis}

Data are expressed as means \pm SEM. The significance of differences between groups was evaluated using one-way analysis of variance with a post hoc Newman-Keul's multiple comparisons test. $P<0.05$ was considered significant.

\section{Results}

\section{Genotyping, Serum G-CSF Concentrations, and} Granulocyte Counts

The allelic status of the mice was determined by PCR analysis of tail DNA (Figure 1A), after which WT and homozygous G-CSF-KO (G-CSF ${ }^{-1-}$ ) mice were used for subsequent experiments. Enzyme-linked immunosorbent assay analysis revealed a G-CSF deficiency in the serum of G-CSF-KO mice (Figure 1B), confirming the original report. ${ }^{8}$ Peripheral granulocyte counts were significantly lower in G-CSF-KO than WT mice, both before and after induction of MI (Figure 1C). Somewhat unexpectedly, the basal activation levels of signaling molecules downstream of G-CSF, including ERK, Akt, and STAT3, were never weaker in G-CSF-KO than WT hearts (Figure 1, D and E), implying the presence of one or more other factors that activate those downstream mediators.

\section{Acute Infarct Size}

One day after infarction, the mean percentage AAR in the left ventricle (AAR/LV) was similar in WT and G-CSF-KO mice $(62 \% \pm 7 \%$ versus $62 \% \pm 4 \% ; P=0.95)$. The infarct size expressed as a percentage of the AAR also did not differ between the two groups (WT versus G-CSF-KO, $56 \% \pm 5 \%$ versus $59 \% \pm 6 \% ; P=0.98$ ) (Figure $2 \mathrm{~A}$ ). Likewise, serum levels of troponin I, an enzyme released from the infarcted myocardium, were similar in WT and G-CSF-KO mice $(62.5 \pm 7.8$ versus $65.0 \pm 7.1 \mathrm{ng} / \mathrm{mL} ; P=0.82) 1$ day after infarction (Figure 2B). Collectively, these data indicate that the acute infarct size did not differ between WT and G-CSFKO mice. The incidence of TUNEL-positive nuclei in the heart also did not differ between the two groups (WT versus G-CSF-KO, $0.07 \% \pm 0.03 \%$ versus $0.08 \% \pm 0.04 \%$; $P=0.86$ ) (Figure $2 \mathrm{C}$ ). On the other hand, immunohistochemical detection of CD45 demonstrated that fewer leukocytes infiltrated the infarcted myocardium in G-CSF-KO $(6.3 \pm 0.63$ cells/HPF $)$ than WT $(8.7 \pm 0.61$ cells/HPF; $P=0.0064$ ) mice (Figure 2D).

\section{Postinfarction Cardiac Remodeling and Dysfunction}

The survival rate 4 weeks after infarction did not differ between groups [WT versus G-CSF-KO, 65\% (13/20) 

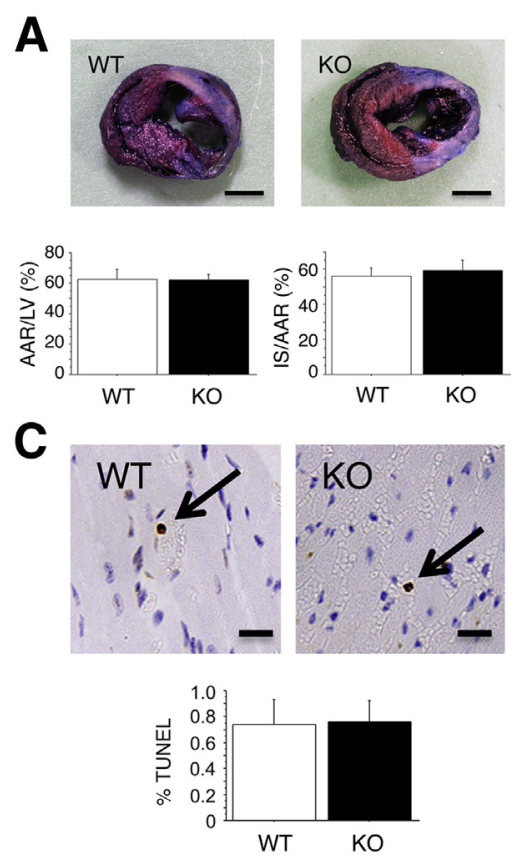

B
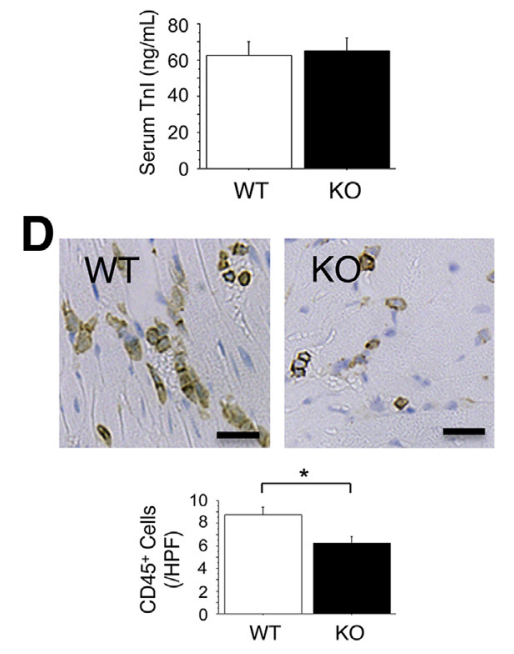

Figure 2 Acute myocardial infarct size on day 1 after coronary artery ligation in wild-type (WT) and granulocyte colony-stimulating factor knockout (G-CSF-KO) mice. A: G-CSFKO and control WT hearts were subjected to ischemia for 24 hours. Gross appearance of transverse ventricular tissue sections after Evans Blue Dye and triphenyltetrazolium chloride staining in WT and G-CSF-KO hearts. The graphs show extent of acute myocardial infarction in WT and G-CSF-KO hearts after coronary artery ligation. The area at risk/left ventricular (LV) area ratio (AAR/LV) and the percentage infarct size/AAR (IS/ AAR). B: Size of the acute infarct assessed 24 hours after infarction on the basis of serum of troponin I levels. C: Terminal deoxynucleotidyl transferase-mediated dUTP nick-end labeling (TUNEL) assay. The graph shows the percentage TUNEL-positive nuclei in the infarcted area of WT and G-CSF-KO hearts. D: Immunostaining for CD45. The graph shows the population of CD45-positive leukocytes in the infarcted area of WT and G-CSFKO hearts. ${ }^{*} P<0.05 . n=6$ each (A-D, WT and K0). Scale bars: $1 \mathrm{~mm}(\mathbf{A}) ; 20 \mu \mathrm{m}$ (C and $\mathbf{D})$. versus $60 \%(12 / 20)]$. Echocardiography and cardiac catheterization revealed that in both groups with 4-week-old MIs, the LV cavity was enlarged and cardiac performance was diminished (ie, LV ejection fraction, LV systolic pressure, and maximal and minimal change in LV pressure over time ( $\pm \mathrm{LV} \mathrm{dP} / \mathrm{dt}$ ) were all reduced). We also found no betweengroup difference in $\mathrm{LV}$ diameter or $\mathrm{LV}$ function assessed on the basis of $\mathrm{LV}$ ejection fraction $+\mathrm{LV} \mathrm{dP/dt}$ and $-\mathrm{LV} \mathrm{dP/dt}$ (Table 1).

Pathological examination confirmed the presence of similar degrees of postinfarction LV remodeling in WT and G-CSF-KO mice (Figure 3A), and similar heart/body weight ratios (WT versus G-CSF-KO, $5.2 \pm 0.16$ versus $5.3 \pm 0.33$ $\mathrm{mg} / \mathrm{g} ; P=0.81$ ) or percentage infarct segments (WT versus G-CSF-KO, $29 \% \pm 8.9 \%$ versus $25 \% \pm 2.9 \% ; P=0.48$ ). Because G-CSF is an important angiogenic factor, we also counted the Flk-1-positive vessels in the postinfarction hearts. We found no difference in the number of vessels in any region between WT and G-CSF-KO hearts (Figure 3B).

\section{Peripheral EPCs and Expression of Angiogenic Factors in G-CSF-KO Mice}

Despite the previously reported beneficial effects of G-CSF on postinfarction cardiac remodeling, ${ }^{3-7}$ we found that the postinfarction process in G-CSF-KO mice did not differ from that in WT mice. This prompted us to examine mice with 4-day-old MIs, in which the remodeling process was ongoing, in an effort to better understand the underlying mechanisms responsible for our findings. In addition to its angiogenic effects, G-CSF is also reportedly a potent stimulator of EPC mobilization. ${ }^{17} \mathrm{We}$, therefore, examined

Table 1 Cardiac Function during Physiological Examinations Performed 4 Weeks after Sham Operation or Coronary Artery Ligation (MI) in WT and G-CSF-KO Mice

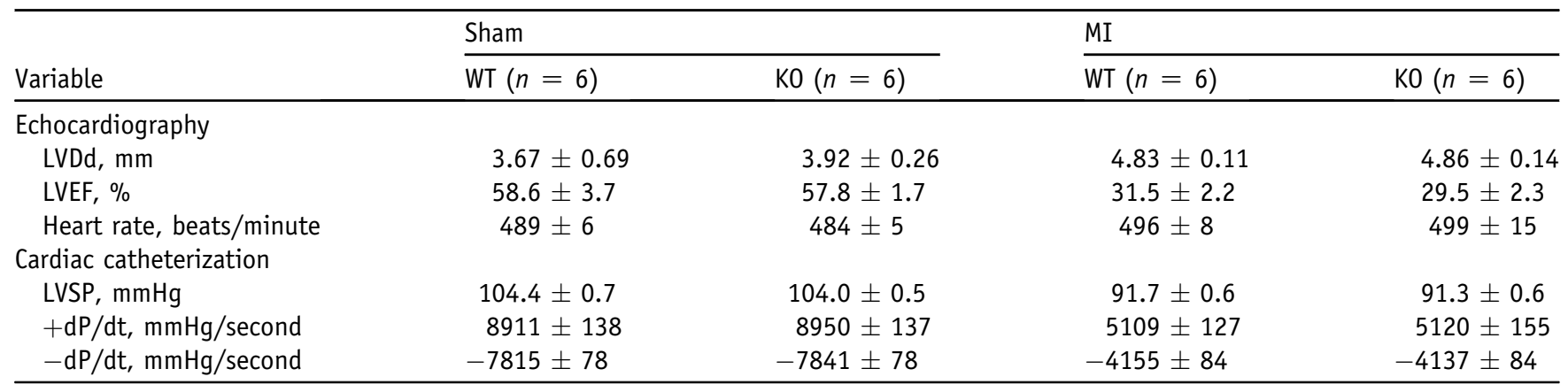

$\pm \mathrm{dP} / \mathrm{dt}$, maximal and minimal change in pressure over time; G-CSF-KO, granulocyte colony-stimulating factor knockout; LVDd, end-diastolic left ventricular diameter; LVEDP, left ventricular end-diastolic pressure; LVEF, left ventricular ejection fraction; LVSP, left ventricular systolic pressure; MI, myocardial infarction; WT, wild type. 

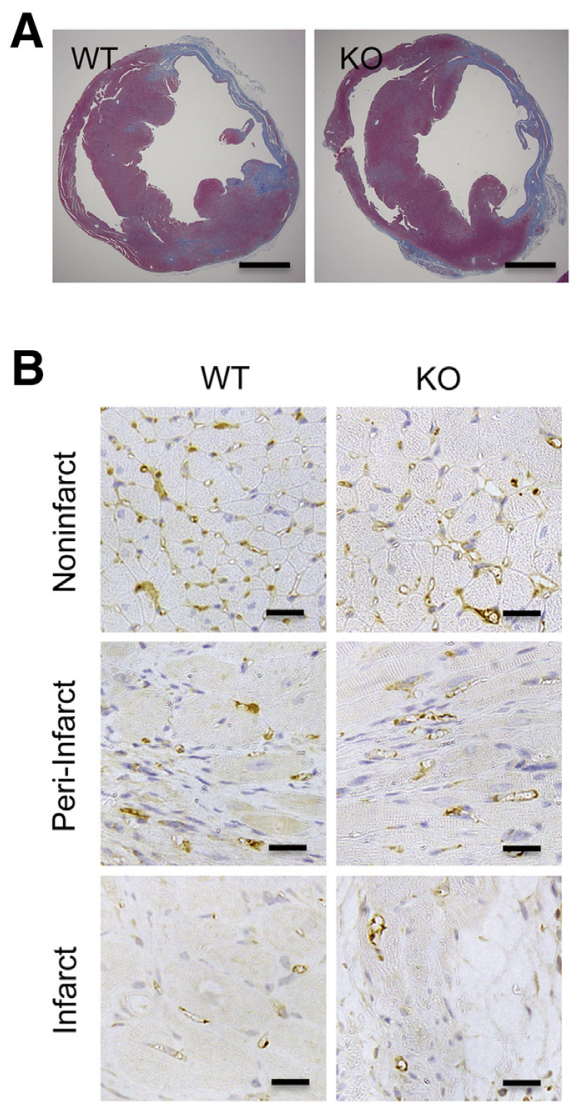
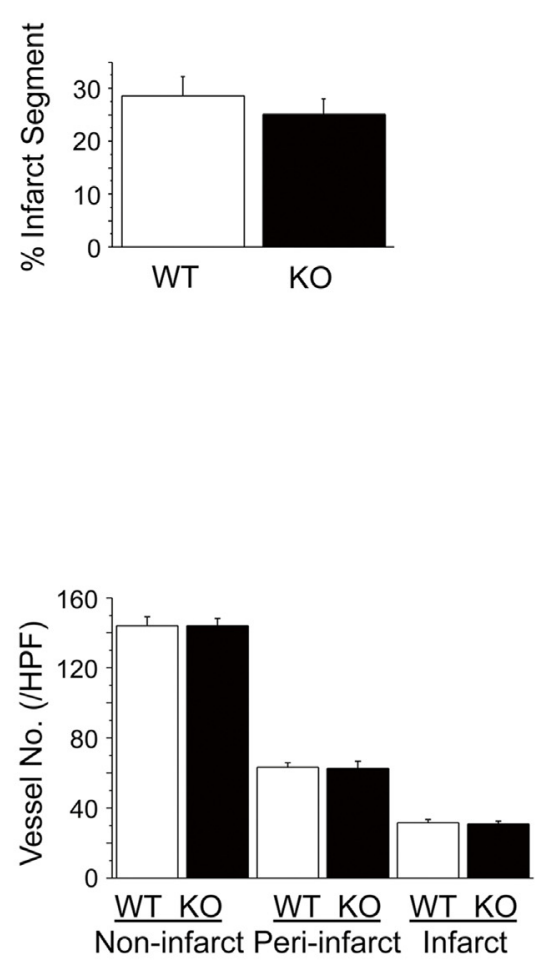

Figure 3 Cardiac pathology 4 weeks after infarction in wild-type (WT) and granulocyte colony-stimulating factor knockout (KO) hearts. A: Transverse ventricular sections stained with Masson's trichrome. The graph shows the percentage infarct segment in the left ventricle. B: Immunostaining for Flk-1. Images show Flk-1-positive blood vessels in peri-infarct regions. The graph shows the numbers of vessels detected. Scale bars: $1 \mathrm{~mm}(\mathbf{A}) ; 20 \mu \mathrm{m}$ (B). peripheral EPCs identified on the basis of their $\mathrm{CD} 34^{+}$/ $\mathrm{Sca}-1^{+}, \mathrm{CD} 34^{+} / \mathrm{Flk}-1^{+}$, or $\mathrm{CD} 34^{+} / \mathrm{CD} 133^{+}$phenotype in WT and G-CSF-KO mice with 4-day-old MIs. Although there was a tendency of more EPCs in the groups with MI in both WT and KO, the difference was insignificant between sham and postinfarction groups, perhaps because of the great variation of the values and small sampling number. There was no difference of EPC number between WT and $\mathrm{KO}$ under both pre-MI and post-MI. In summary, we found no significant differences in the size of the EPC fraction among peripheral blood mononuclear cells between the groups studied on day 4 after surgery (Figure 4).

We next investigated the cardiac expression of other angiogenic factors, including angiopoietin-1, HGF, HIF- $1 \alpha$, IGF-1, and VEGF in G-CSF-KO mice. Western blot analysis showed similar levels of angiopoietin-1, HGF, HIF-1 $\alpha$, and IGF-1 between WT and KO, whereas only myocardial IGF-1 among them became greater after infarction (Figure 5A). On the other hand, greater expression of VEGF was revealed in sham-operated on hearts from G-CSF-KO than WT hearts (Figure 5A), and VEGF expression was augmented still further in G-CSF-KO hearts after MI (4 days after infarction). Immunohistochemistry showed that VEGF was expressed on endothelial cells and interstitial mononuclear cells in both WT and KO and in both sham and postinfarction (Figure 5B). Furthermore, myocardial ERK and STAT3 were both activated after infarction, and their activities were greater in G-CSF-KO than WT hearts (Figure 1D).

Molecular Mechanisms for Augmented VEGF Expression in G-CSF-KO Mice

We investigate the molecular mechanism for the enhanced VEGF expression in G-CSF-KO mice. Monocytes have an important role in postischemic vascular remodeling through the production of diverse growth factors, including VEGF. ${ }^{19}$ Measurement of peripheral monocytes revealed that their population was greater in KO 4 days after infarction but not preinfarction and 1 day after infarction (Figure 6A). On the other hand, although monocytes/macrophages have a functional G-CSF receptor, the production of VEGF by these cells was demonstrated to be independent of G-CSF stimulation. ${ }^{20}$ In addition, mast cells were demonstrated to accumulate in ischemic tissues and secrete VEGF. ${ }^{19,21}$ Our immunohistochemistry showed VEGF expression not only in endothelial cells but also myocardial interstitial mononuclear cells, as mentioned (Figure 5B). $\mathrm{We}$, therefore, assessed monocyte/macrophage and mast cell population in both WT and KO and in both sham and postinfraction. Monocyte/macrophage population was found increased after infarction in both WT and KO, but there was no difference in the population between WT and KO (Figure 6B). No difference was noted in mast cell 


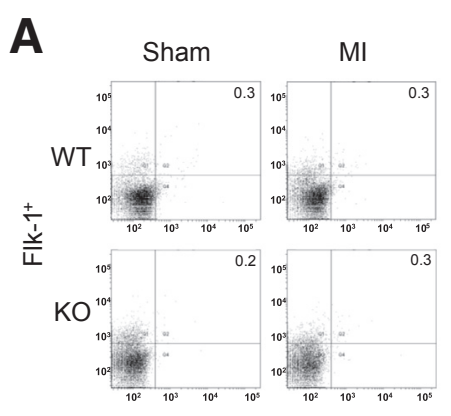

$\mathrm{CD}^{+} 4^{+}$

B

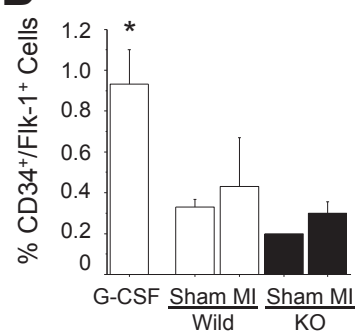

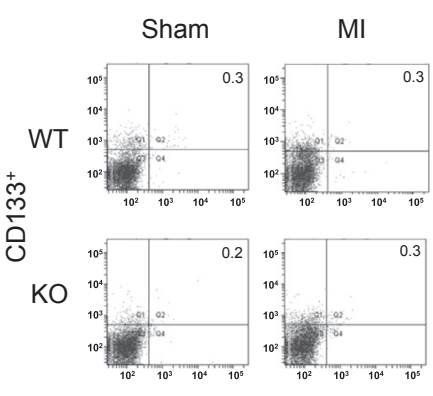

$\mathrm{CD} 34^{+}$

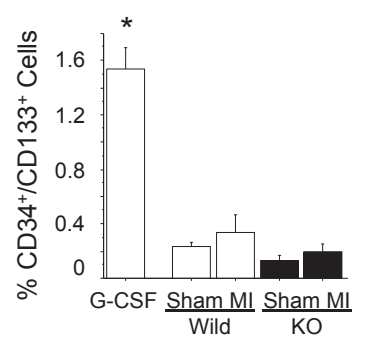

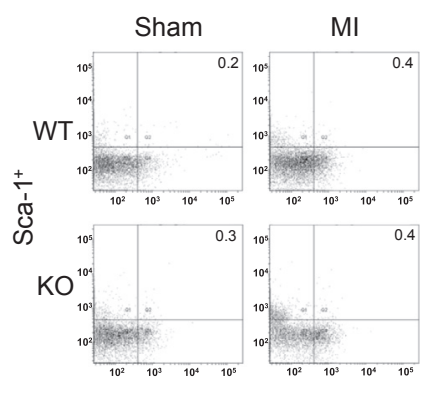

$\mathrm{CD}^{+} 4^{+}$

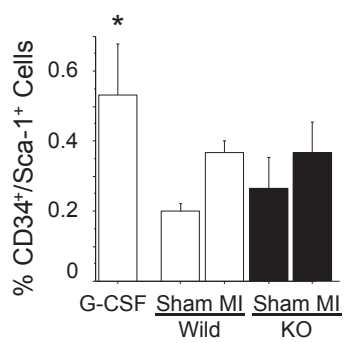

Figure 4 Endothelial progenitor cell mobilization in wild-type (WT) and granulocyte colony-stimulating factor knockout (G-CSF-KO) mice 4 days after surgery. A: Fluorescence-activated cell sorting analysis of $\mathrm{CD} 34^{+} / \mathrm{Flk}-1^{+}$cell mobilization 4 days after infarction. B: Graphs showing the percentages of $\mathrm{CD} 34^{+} / \mathrm{Flk}-1^{+}$cells, $\mathrm{CD} 34^{+} /$ $\mathrm{CD} 33^{+}$cells, and $\mathrm{CD} 34^{+} / \mathrm{Sca}-1^{+}$cells among total peripheral blood mononuclear cells. ${ }^{*} P<0.05$ versus all others. $n=3$ each $(\mathbf{A}$ and $\mathbf{B}$, WT and K0 mice). APC, allophycocyanin; FITC, fluorescein isothiocyanate; MI, myocardial infarction.

population between $\mathrm{WT}$ and $\mathrm{KO}$ and between sham and postinfarction (Figure 6C).

We next performed microarray analysis of heart tissue of the mice. We especially checked various angiogenesisrelated factors and, to our surprise, the level of VEGF mRNA was not increased in G-CSF-KO compared with WT but similar between them (Figure 7A). Levels of all other related genes were not different either between $\mathrm{KO}$ and WT under normal condition. Hearts from KO 2 days after infarction showed a significant up-regulation of six genes compared with those from sham-operated on KO, which encode CXCL16, CXCL4, CYR61, HGF, thrombospondin 2 , and tissue inhibitor of metalloproteinases 1, but not VEGF. These results suggest a possibility that G-CSF regulates VEGF expression at the post-transcriptional level under both normal and ischemic conditions. To check this hypothesis, we next treated mice with G-CSF $(100 \mu \mathrm{g} / \mathrm{kg}$ i.p. for 3 days) and examined myocardial expression of VEGF. We found that myocardial expression of VEGF significantly decreased in KO by the G-CSF treatment. To our surprise, the level of myocardial VEGF in KO decreased nearly to that of WT (Figure 7B). These findings indicate that G-CSF post-transcriptionally down-regulates VEGF.

\section{Effect of VEGF Inhibition on Postinfarction Process}

The findings summarized above suggest that overexpressed VEGF compensates for the G-CSF defect, thereby preventing the exacerbation of postinfarction cardiac remodeling and dysfunction in G-CSF-KO mice. We inhibited the VEGF signal using an anti-VEGF antibody (bevacizumab) during the postinfarction process in WT and G-CSF-KO mice. The mice were treated with bevacizumab for 4 weeks, beginning 1 day after surgery. Four weeks after infarction, echocardiography and cardiac catheterization revealed significant aggravation of LV remodeling and dysfunction in G-CSF-KO mice treated with bevacizumab, compared with control G-CSF-KO mice (Table 2). By contrast, bevacizumab had no effect on postinfarction LV remodeling or function in WT mice. Histological analysis confirmed the LV dilatation in G-CSF-KO mice treated with bevacizumab. Postinfarction G-CSF-KO hearts treated with bevacizumab showed greater percentage infarct segments than salinetreated G-CSF-KO hearts and had more elongated infarct segments and thinner infarct walls (Figure 8A). In the infarct scar treated with bevacizumab, the G-CSF-KO hearts contained a significantly smaller population of nonmyocytes than the WT hearts $(259 \pm 22$ versus $459 \pm 69$ cells/HPF; $P=0.0331$ ) (Figure 8B). In addition, vascular development was significantly poorer at the infarct and in the border regions in bevacizumab-treated G-CSF-KO hearts (Figure 8C).

To explore the reason for the poor development of blood vessels in the postinfarction G-CSF-KO hearts treated with bevacizumab, we assessed cell proliferation and apoptosis among vascular endothelial cells in hearts 4 days after infarction. Within the granulation tissue of bevacizumabtreated G-CSF-KO hearts, the incidence of Ki-67-positive proliferating cells among lectin-positive endothelial cells was significantly lower than control (saline versus bevacizumab, $0.31 \% \pm 0.03 \%$ versus $0.09 \% \pm 0.01 \% ; P<0.0001)$. In addition, the incidence of TUNEL-positive apoptotic cells 

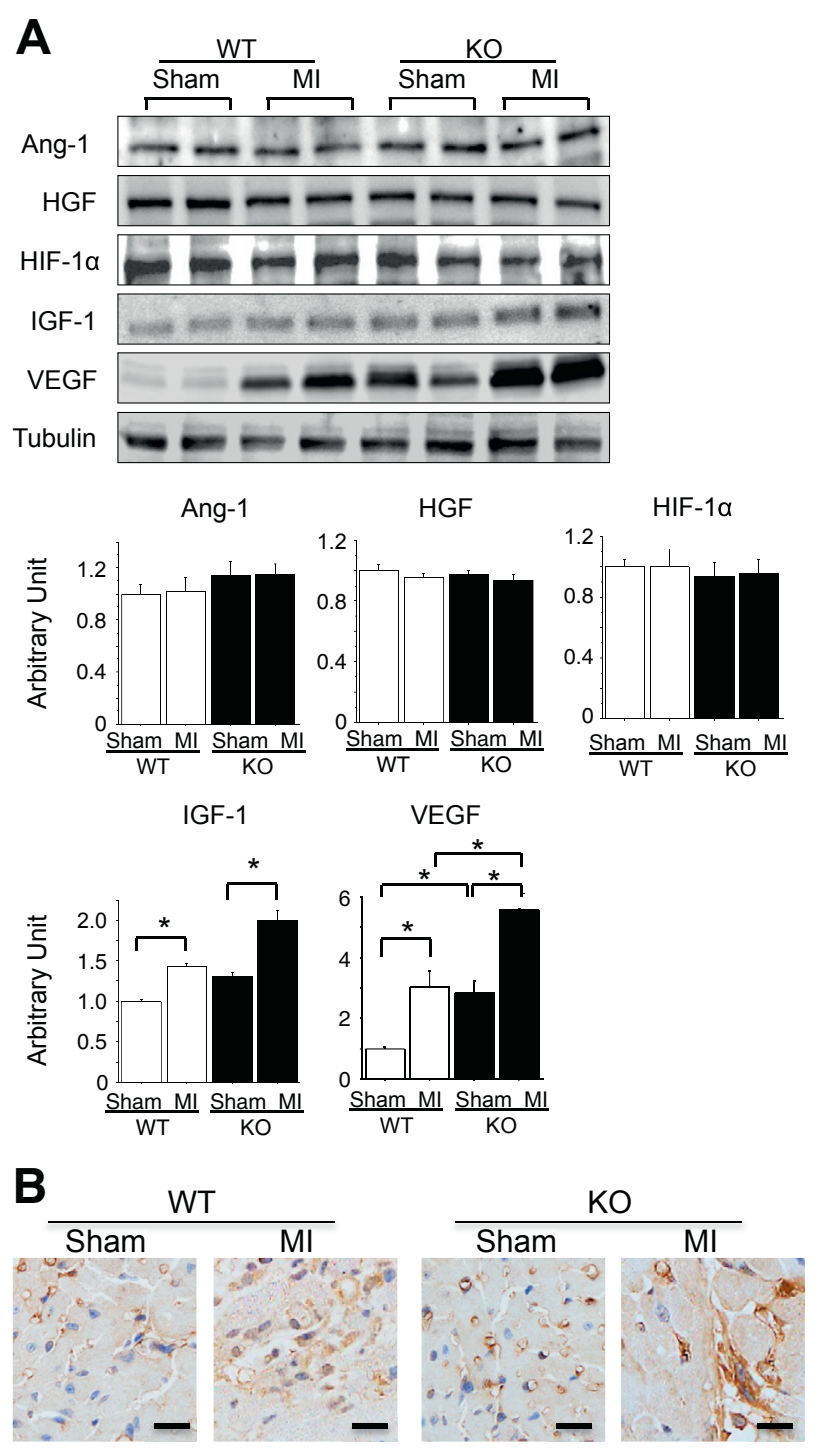

Figure 5 Expression of angiogenic factors in the hearts of wild-type (WT) and granulocyte colony-stimulating factor knockout (KO) mice. A: Western blots for angiopoietin (Ang)-1, hepatocyte growth factor (HGF), insulin-like growth factor-1 (IGF-1), and vascular endothelial growth factor (VEGF). B: Immunostaining for VEGF in hearts 4 days after sham operation or coronary artery ligation [myocardial infarction (MI)]. Images in cases of MI show the area bordering infarct. ${ }^{*} P<0.05$. Scale bar $=20 \mu \mathrm{m}$. HIF, hypoxia-inducible factor.

among lectin-positive endothelial cells was significantly higher in bevacizumab- than saline-treated G-CSF-KO hearts (saline versus bevacizumab, $0.78 \% \pm 0.24 \%$ versus $1.9 \% \pm 0.24 \% ; P=0.003$ ) (Figure 9). These findings suggest that by reducing endothelial cell proliferation and increasing apoptosis during the subacute stage of infarction, bevacizumab treatment led to poorer vascular development at the chronic stage. Similarly, double immunostaining for myoglobin and Ki-67 or TUNEL showed that bevacizumab reduced proliferation (saline versus bevacizumab, $0.028 \% \pm 0.006 \%$ versus $0.014 \% \pm 0.003 \% ; P=0.046$ ) while increasing apoptosis among granulation tissue cells (saline versus bevacizumab, $0.010 \% \pm 0.004 \%$ versus
$0.024 \% \pm 0.006 \% ; P=0.0045$ ) (Figure 10). Both Ki-67 and TUNEL positivity were extremely low in myoglobinpositive surviving cardiomyocytes in both WT and G-CSFKO mice.

\section{Discussion}

Evidence from several studies suggests that supplemental treatment with G-CSF can alleviate postinfarction cardiac remodeling and heart failure. ${ }^{3-7}$ All of those studies suggest that G-CSF plays an important role during the postinfarction process in the heart; one would, therefore, assume that G-CSF deficiency in the postinfarction heart would exacerbate postinfarction cardiac remodeling. In addition, a more recent study suggested that G-CSF is also critically involved in cardiac development. ${ }^{22}$ Therefore, our main finding that postinfarction cardiac remodeling in G-CSF-KO mice

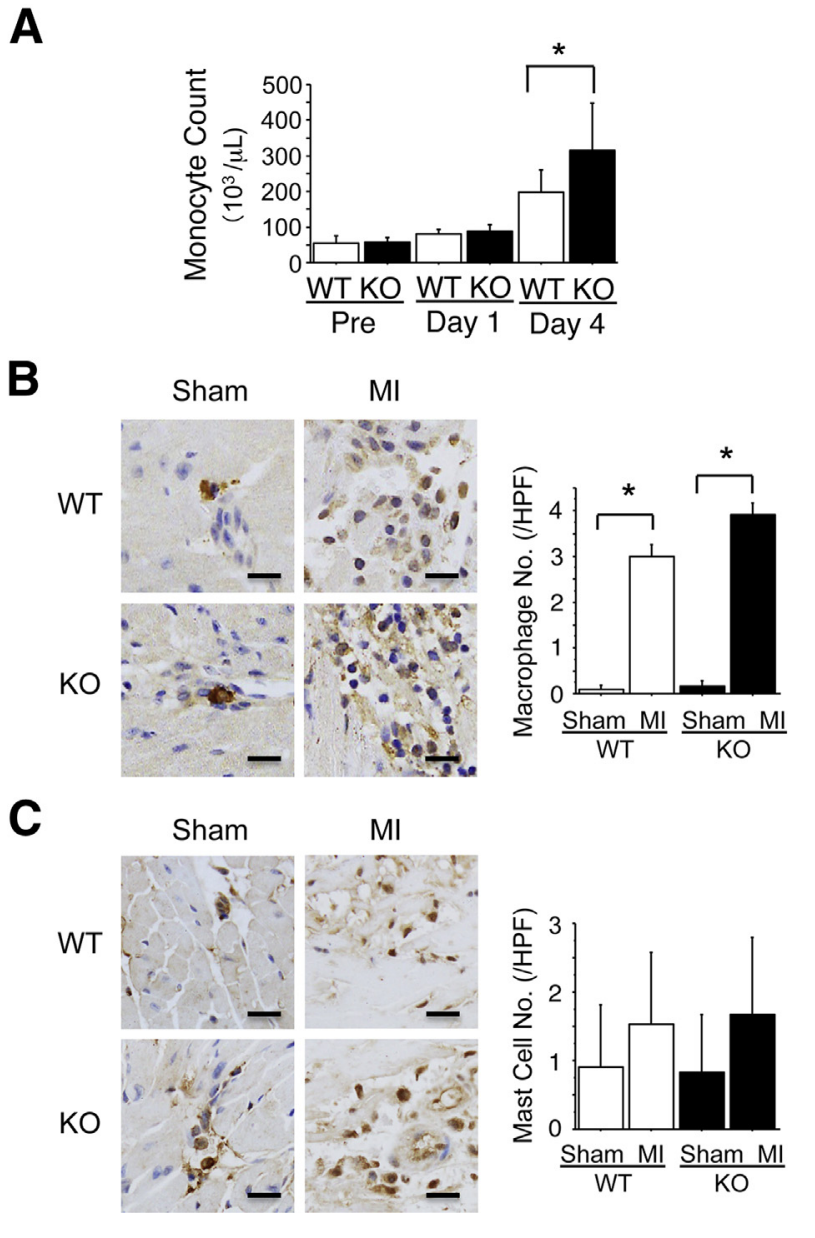

Figure 6 Peripheral monocytes and myocardial macrophages and mast cells. A: Monocyte counts in the peripheral blood before the operation and on days 1 and 4 after infarction in wild-type (WT) and granulocyte colonystimulating factor knockout (K0) mice. B: Immunostaining for $\mathrm{F} 4 / 80$ to detect macrophages in hearts 4 days after sham operation or coronary artery ligation [myocardial infarction (MI)]. C: Immunostaining for mast cells in hearts 4 days after sham operation or coronary artery ligation (MI). Images in cases of infarction show the area bordering infarct. ${ }^{*} P<0.05 . n=3$ each (A, WT and KO). Scale bar $=20 \mu \mathrm{m}$. HPF, high-power field. 
A

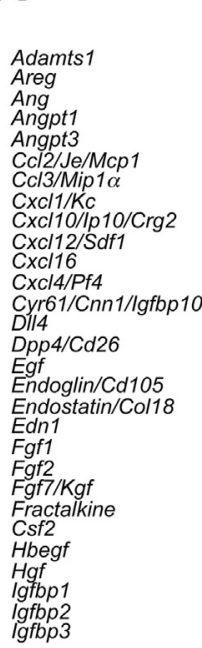

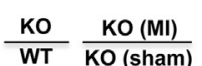

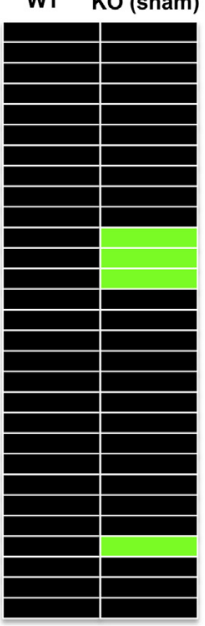

B
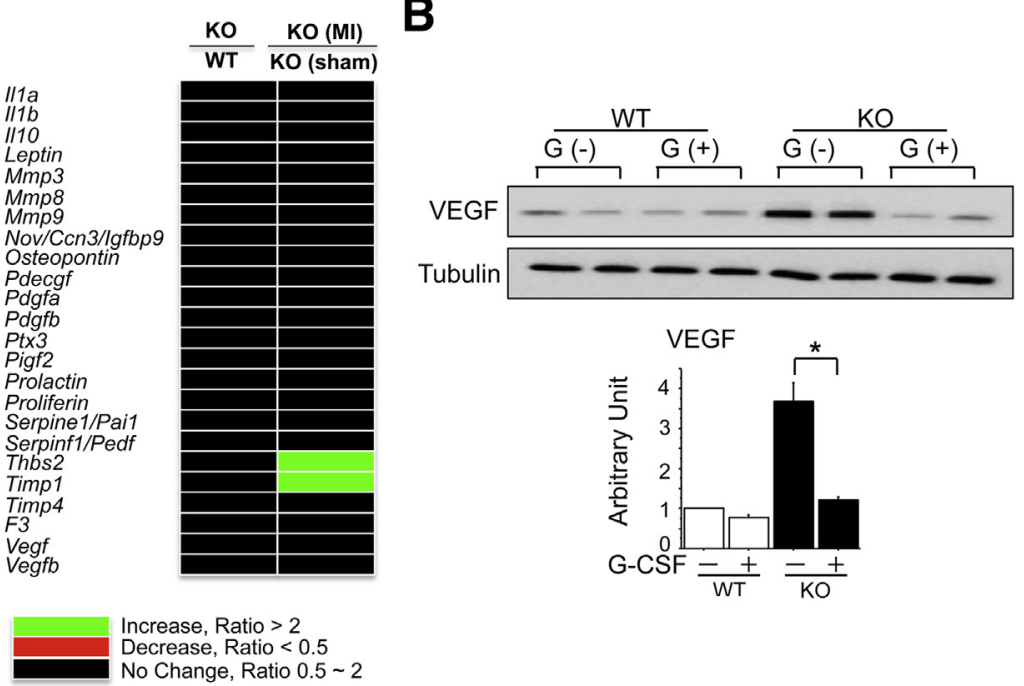

Figure 7 Microarray data and effect of the treatment with granulocyte colony-stimulating factor (G-CSF) on myocardial vascular endothelial growth factor (VEGF) expression. A: Gene expression changes measured by microarray of angiogenesis-related factors, including VEGF [ie, ADAM metallopeptidase with thrombospondin type 1 motif (ADAMTS1), amphiregulin, angiogenin, angiopoietin-1, angiopoietin-3, chemokine ligand (CCL) 2/JE/MCP-1, CCL3/macrophage inflammatory protein (MIP)-1 $\alpha$, CXCL1/KC, CXCL10/IP-10/CRG-2, CXCL12/SDF-1, CXCL16, CXCL4/PF4, Cyr61/CNN1/IGFBP-10, DLL4, DPPIV/CD26, epidermal growth factor (EGF), endoglin/CD105, endostatin/collagen XVIII, endothelin-1, fibroblast growth factor (FGF) acidic, FGF basic, FGF-7/KGF, fractalkine, granulocytemacrophage (GM)-CSF, HB-EGF, hepatocyte growth factor (HGF), IGFBP-1, IGFBP-2, IGFBP-3, IL-1 $\alpha$, IL-1 $\beta$, IL-10, leptin, matrix metalloproteinase (MMP)-3, MMP-8, MMP-9, NOV/CCN3/IGFBP-9, osteopontin, PD-ECGF, platelet-derived growth factor (PDGF)-AA, PDGF-AB/BB, pentraxin-3, PIGF-2, prolactin, proliferin, serpin E1/PAI-1, serpin F1/PEDF, thrombospondin-2, tissue inhibitor of metalloproteinases (TIMP)-1, TIMP-4, coagulation factor III, VEGF, and VEGF-B]; the encoding genes are, respectively, Adamts1, Areg, Ang, Angpt1, Angpt3, Ccl2, Ccl3, Cxcl1, Cxcl10, Cxcl12, Cxcl16, Cxcl4, Egf, Endoglin, Endostatin, Edn1, Fgf1, Fgf2, Fgf7, Fractalkine, Csf2, Hbegf, Hgf, Igfbp1, Igfbp2, Igfbp3, Il1a, Il1b, Il10, Leptin, Mmp3, Mmp8, Mmp9, Nov, Osteopontin, Pdecgf, Pdgfa, Pdgfb, Ptx3, Pigf2, Prolactin, Proliferin, Serpine1, Serpinf1, Thbs2, Timp1, Timp4, F3, Vegf, and Vegfb. Genes up-regulated by more than twofold, those down-regulated to less than a half, and those unchanged are highlighted, respectively, in green (six genes), red (no genes), and black (the rest). B: Western blot for VEGF in the heart of wildtype (WT) and knockout (K0), with or without G-CSF treatment. ${ }^{*} P<0.05 . n=3$ each (B, WT and K0). CNN1, calponin 1 , basic, smooth muscle; CCN3, cysteinerich61/connective tissue growth factor/nephroblastoma overexpressed 3; CRG-2, cytokine responsive gene 2; DLL4, delta-like ligand 4; DPPIV, dipeptidyl peptidase IV; HB-EGF, heparin binding epidermal growth factor-like growth factor; IGFBP-10, insulin-like growth factor-binding protein 10; IP-10, interferon- $\gamma$ -inducible protein-10; KC, keratinocyte chemoattractant; KGF, keratinocyte growth factor; MCP-1, monocyte chemotactic protein-1; MI, myocardial infarction; NOV, nephroblastoma overexpressed; PAI-1, plasminogen activator inhibitor-1; PD-ECGF, platelet-derived endothelial cell growth factor; PEDF, pigment epithelium-derived factor; PF4, platelet factor 4; PIGF-2, placental growth factor 2; and SDF-1, stromal cell-derived factor 1.

does not differ from that in WT mice was somewhat unexpected.

\section{VEGF Is Overexpressed in the Hearts of G-CSF-KO Mice}

VEGF is a highly specific mitogen for vascular endothelial cells, ${ }^{23-25}$ and its expression is up-regulated in response to hypoxia, activated oncogenes, and various cytokines. VEGF induces angiogenesis and plays a central role in the regulation of vasculogenesis. A screening for angiogenic growth factors in the present study revealed markedly greater expression of VEGF in G-CSF-KO than WT hearts, which was further increased after infarction. This suggests that the overexpression of VEGF compensates for the lack of

Table 2 Cardiac Function 4 Weeks after Infarction in WT or G-CSF-KO Mice Treated with Saline or Bevacizumab

\begin{tabular}{|c|c|c|c|c|}
\hline \multirow[b]{2}{*}{ Variable } & \multicolumn{2}{|l|}{ WT } & \multicolumn{2}{|l|}{ G-CSF-KO } \\
\hline & Vehicle $(n=6)$ & Bevacizumab $(n=6)$ & Vehicle $(n=6)$ & Bevacizumab $(n=6)$ \\
\hline \multicolumn{5}{|l|}{ Echocardiography } \\
\hline LVEF, \% & $32.1 \pm 1.7$ & $31.7 \pm 3.3$ & $31.3 \pm 1.7$ & $25.0 \pm 1.1^{*}$ \\
\hline Heart rate, beats/minute & $500 \pm 4$ & $504 \pm 7$ & $509 \pm 4$ & $509 \pm 4$ \\
\hline \multicolumn{5}{|l|}{ Cardiac catheterization } \\
\hline$-\mathrm{dP} / \mathrm{dt}, \mathrm{mmHg} /$ second & $-4141 \pm 69$ & $-4103 \pm 49$ & $-4152 \pm 51$ & $-3691 \pm 56^{*}$ \\
\hline
\end{tabular}

${ }^{*} P<0.05$ compared with the vehicle-treated $\mathrm{K} 0$ group.

$\pm \mathrm{dP} / \mathrm{dt}$, maximal and minimal change in pressure over time; G-CSF-KO, granulocyte colony-stimulating factor knockout; LVDd, end-diastolic left ventricular diameter; LVEDP, left ventricular end-diastolic pressure; LVEF, left ventricular ejection fraction; LVSP, left ventricular systolic pressure; WT, wild type. 
A

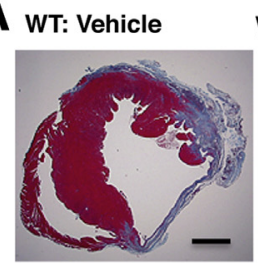

KO: Vehicle

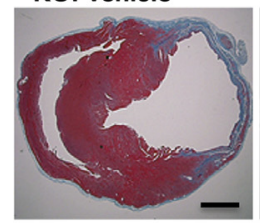

WT: aVEGF

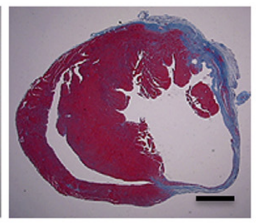

KO: aVEGF

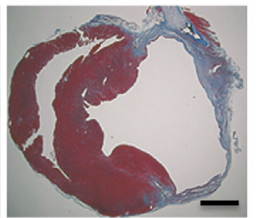

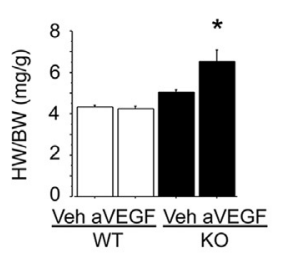
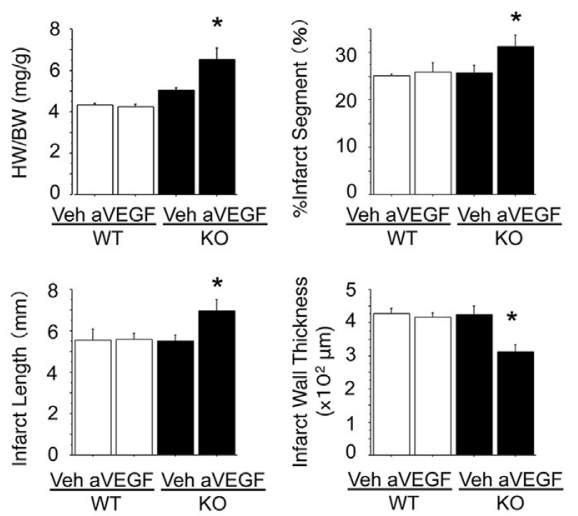

B

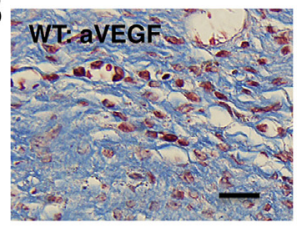

C

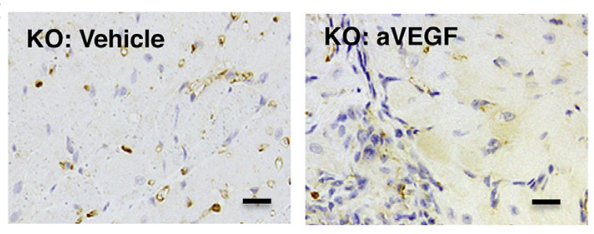

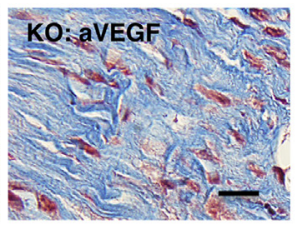

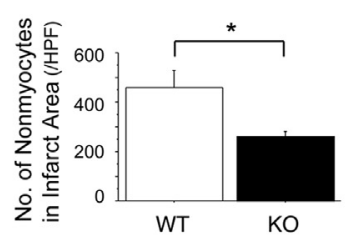

Non-MI Area

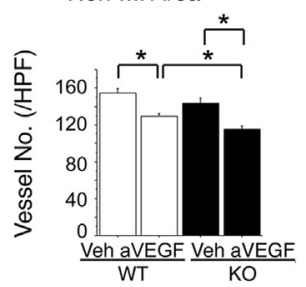

Figure 8 Cardiac pathology 4 weeks after infarction in wild-type (WT) and granulocyte colony-stimulating factor knockout (KO) mice treated with saline or bevacizumab. A: Transverse ventricular sections stained with Masson's trichrome. Graphs show heart weight (HW)/body weight (BW) ratios, percentage infarct segment in the left ventricle, infarct segment length, and infarct wall thickness. B: Images showing the infarct scar tissue from WT and KO hearts after bevacizumab treatment (Masson's trichrome stain). The graph shows noncardiomyocyte population in the infarct scar. C: Immunostaining for Flk-1. Images show Flk-1-positive blood vessels in peri-infarct regions. The graphs show numbers of vessels per high-power field (HPF). ${ }^{*} P<0.05$. Scale bars: $1 \mathrm{~mm}$ (A); $20 \mu \mathrm{m}$ (B and C). aVEGF, anti-vascular endothelial growth factor treatment; MI, myocardial infarction; Veh, vehicle.
G-CSF in both uninjured and infarcted G-CSF-KO hearts. Consistent with that idea, inhibition of VEGF signal transduction using bevacizumab greatly exacerbated postinfarction LV remodeling in G-CSF-KO mice. Moreover, several signaling molecules downstream of G-CSF, including ERK, Akt, and STAT3, are known to be also activated by VEGF. ${ }^{26,27}$

Remaining unknown was the molecular mechanisms by which the overexpression of VEGF is mediated in the G-CSF-KO mice. The population of peripheral monocytes capable of secreting VEGF was greater in KO 4 days after infarction but not preinfarction and 1 day after infarction. On the other hand, myocardial populations of macrophages and mast cells, which also can secrete VEGF, were not greater in KO compared with WT in both sham and postinfarction. Those findings on monocytes/macrophages and mast cells unfortunately cannot explain augmented expression of VEGF in sham-operated on KO. Microarray analysis unexpectedly showed no difference of VEGF mRNA level between WT and KO. On the other hand, we found that myocardial VEGF was significantly decreased by administration of G-CSF in KO but not in WT. These findings indicate that G-CSF post-transcriptionally down-regulates VEGF. And, therefore, G-CSF-KO mice display increased VEGF expression because of the lack of G-CSF. On the other hand, in WT, endogenous G-CSF might already have sufficiently suppressed VEGF and, thus, exogenous G-CSF could not have displayed additional effect.
It may seem somewhat curious that myocardial HIF- $1 \alpha$ expression was not elevated 2 days after infarction (Figure 5A) because hypoxia is known to activate HIF- $1 \alpha$, an inducer of VEGF. We further examined HIF- $1 \alpha$ expression 1 day after infarction, which was not elevated, either (data not shown). A recent study examined time course of HIF- $1 \alpha$ expression, along with galectin-1, in mouse hearts after MI and reported that expression of HIF- $1 \alpha$ is augmented, but this increase was transient; it was significantly increased at 20 minutes but returned to baseline at 30 minutes after the coronary artery ligation. Our findings are consistent with this report. ${ }^{28}$

\section{Compensatory Effects of Overexpressed VEGF in Postinfarction Hearts}

An earlier study reported that treatment with recombinant G-CSF inhibited apoptosis of ischemic cardiomyocytes, thereby significantly reducing the size of acute MIs in mice. ${ }^{6}$ In a later study, however, no anti-apoptotic effect of G-CSF was detected with cardiomyocytes subjected to an ischemic insult. ${ }^{29}$ Consistent with that later study, we found that the sizes of acute infarcts in G-CSF-KO mice overexpressing VEGF were comparable to those in WT mice, and there was also no difference in the incidences of myocardial TUNEL positivity.

So how could overexpressed VEGF compensate for a G-CSF deficiency in postinfarction mice? Inhibition of VEGF signal transduction using bevacizumab altered the 


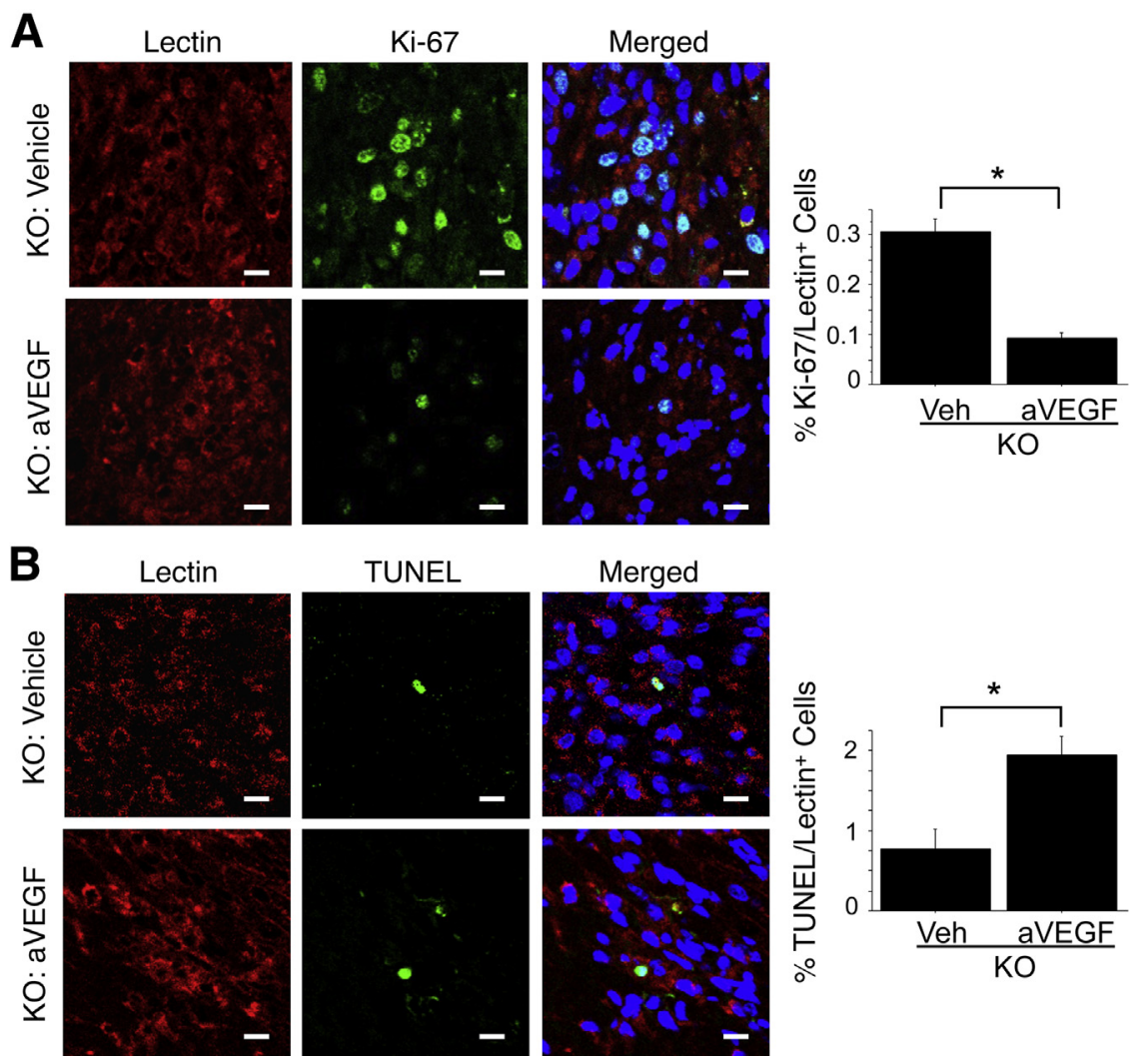

Figure 9 Effect of bevacizumab on proliferation and apoptosis of vascular endothelial cells in granulocyte colony-stimulating factor knockout (KO) hearts at the subacute stage of infarction (4 days after infarction). A: Proliferation assessed on the basis of Ki-67 immunostaining of lectinpositive vascular endothelial cells. Representative confocal images and graphs showing the incidence of Ki-67 positivity among vascular endothelial cells. B: Apoptosis assessed using terminal deoxynucleotidyl transferase-mediated dUTP nick-end labeling (TUNEL) assays with lectin-positive vascular endothelial cells. Representative confocal images and graphs showing the incidence of TUNEL positivity among vascular endothelial cells. ${ }^{*} P<0.05$. Scale bar $=20 \mu \mathrm{m}(\mathbf{A}$ and $\mathbf{B})$. aVEGF, anti-vascular endothelial growth factor treatment; Veh, vehicle.

geometry of the infarct scar (ie, the infarct segment was thinner and had a greater circumferential length during the chronic stage). This is noteworthy because wall stress is directly proportional to cavity diameter and inversely proportional to wall thickness (Laplace's law), and because wall stress and LV dilatation have a vicious relationship and exacerbate one another. ${ }^{29,30}$ It is, thus, conceivable that the observed change in infarct geometry would greatly worsen the hemodynamic state of the heart. In addition, the infarct scar tissue was qualitatively altered by treatment with bevacizumab. We observed fewer nonmyocytes, including a less developed vasculature, within the infarct scar in
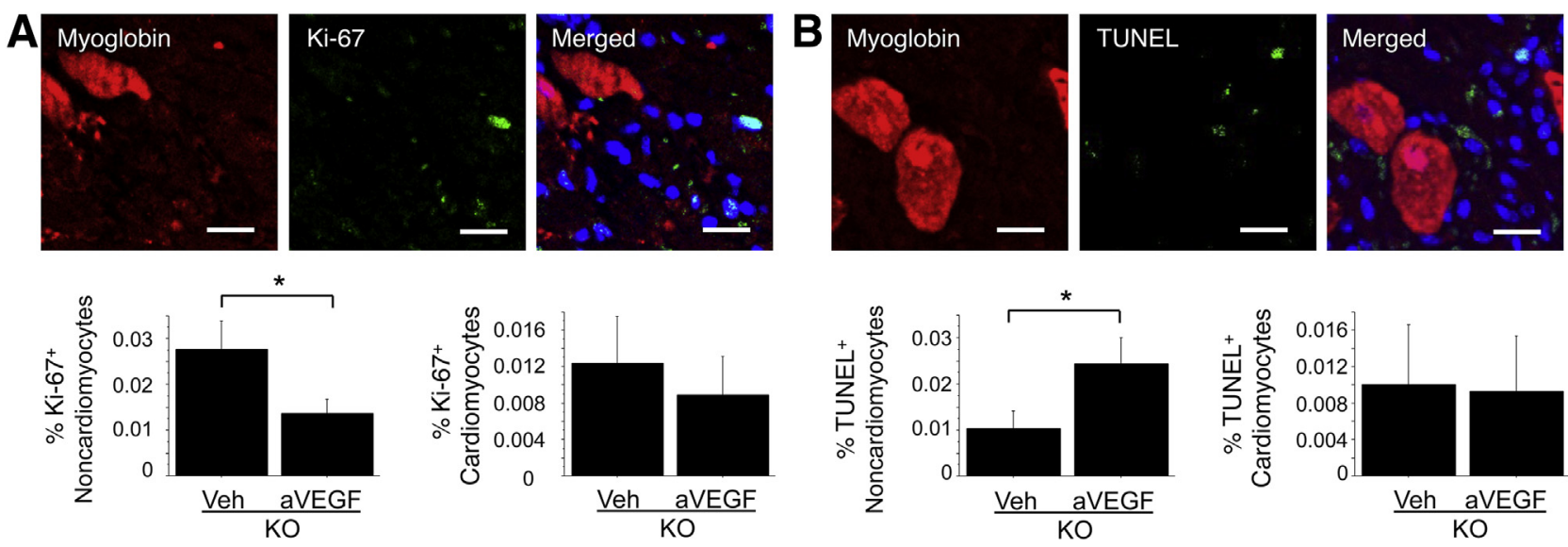

Figure 10 Cell proliferation and apoptosis 4 days after infarction in wild-type (WT) and granulocyte colony-stimulating factor knockout (K0) mice treated with saline or bevacizumab. A: Double immunostaining for Ki-67 (green) and myoglobin (red) to detect proliferating noncardiomyocyte granulation tissue cells (not stained red). Confocal images show representative images from WT mice treated with saline. The graph compares the percentage of Ki-67-positive noncardiomyocytes and cardiomyocytes. B: Double immunostaining for terminal deoxynucleotidyl transferase-mediated dUTP nick-end labeling (TUNEL; green) and myoglobin (red) to detect apoptotic noncardiomyocytes and cardiomyocytes. The graph compares the percentage TUNEL-positive noncardiomyocytes and cardiomyocytes. ${ }^{*} P<0.05$. Scale bar $=20 \mu \mathrm{m}(\mathbf{A}$ and $\mathbf{B})$. aVEGF, anti-vascular endothelial growth factor treatment; Veh, vehicle. 
bevacizumab-treated hearts 4 weeks after infarction. Most nonmyocytes are destined to eventually disappear via apoptosis during the natural course of postinfarction healing, ${ }^{31,32}$ but we found that apoptosis was augmented in the bevacizumab-treated G-CSF-KO hearts during the subacute stage (4 days after infarction). We previously reported that anti-apoptotic treatment with a pan-caspase inhibitor or with soluble Fas gene delivery preserves the nonmyocyte (granulation tissue cell) population in the infarct area and significantly mitigates postinfarction cardiac remodeling and dysfunction. ${ }^{33,34}$ Conversely, bevacizumab treatment significantly reduced cell proliferation, including proliferation of vascular endothelial cells in the infarct area. Together, the enhanced apoptosis and suppressed proliferation among granulation tissue cells during the subacute stage appear to mediate the observed reduction in the nonmyocyte population within the scar tissue at the chronic stage. This likely causes thinning of the infarct wall, increasing wall stress and aggravating cardiac remodeling.

It seems strange that WT animals treated with bevacizumab did not display changes in infarct size nor LV function when compared with vehicle-treated animals, despite VEGF levels being elevated not only in KO but also in WT after MI. However, although VEGF suppression by bevacizumab significantly decreased the vessel population in the postinfarction WT heart, that decrease was significantly milder compared with $\mathrm{KO}$ (Figure 8C). It is assumed that such a mild decrease could not have overcome the threshold for worsening infarct size and LV function in WT.

\section{Possible Mechanisms by Which Overexpressed VEGF Alters Myocardial Cell Dynamics during the Subacute Stage of Infarction}

Late reperfusion, beyond the window for myocardial salvage, reduces both LV remodeling and mortality after MI (open artery hypothesis), ${ }^{35,36}$ and several possible mechanisms by which an open infarct-related artery could confer benefit in ways other than salvaging ischemic myocardium have been proposed. Increased wall thickness without a reduction in the infarct scar area is reportedly one of the morphological characteristics of postinfarction hearts receiving late reperfusion. ${ }^{37-40}$ We reported that late reperfusion of the infarct area 24 hours after MI promoted cell proliferation and inhibited apoptosis among granulation tissue cells in rats, which we suppose contributed significantly to the formation of a thick, cell-rich infarct scar during the chronic stage. ${ }^{41,42}$ Of note is the striking similarity between the effects of late reperfusion and VEGF overexpression on infarct tissue dynamics. As mentioned, VEGF is a potent inducer of angiogenesis and vasculogenesis, and in the present study, its inhibition diminished vascularization in the postinfarction hearts of G-CSF-KO mice, at least in part through suppression of cell proliferation and promotion of apoptosis in the granulation tissue during the subacute stage. We also found that vascular development within the infarct and border areas was poor 4 days after infarction in G-CSF-KO hearts treated with bevacizumab. A late reperfusion-like effect may, thus, be one of the mechanisms mediated by VEGF overexpression, which appears to compensate for the G-CSF deficit in G-CSF-KO mice.

\section{Acknowledgments}

We thank Natsuko Ishigami, Chika Ogawa, and Megumi Minagawa (Gifu University) and Rieko Hori and Norie Soga (Asahi University) for their assistance and Koh Ono (Kyoto University Graduate School of Medicine) for helpful discussion.

\section{References}

1. Pfeffer MA: Left ventricular remodeling after acute myocardial infarction. Annu Rev Med 1995, 46:455-466

2. Reimer KA, Vander Heide RS, Richard VJ: Reperfusion in acute myocardial infarction: effect of timing and modulating factors in experimental models. Am J Cardiol 1993, 72:13G-21G

3. Orlic D, Kajstura J, Chimenti S, Limana F, Jakoniuk I, Quaini F, Nadal-Ginard B, Bodine DM, Leri A, Anversa P: Mobilized bone marrow cells repair the infarcted heart, improving function and survival. Proc Natl Acad Sci U S A 2001, 98:10344-10349

4. Kawada H, Fujita J, Kinjo K, Matsuzaki Y, Tsuma M, Miyatake H, Muguruma Y, Tsuboi K, Itabashi Y, Ikeda Y, Ogawa S, Okano H, Hotta T, Ando K, Fukuda K: Nonhematopoietic mesenchymal stem cells can be mobilized and differentiate into cardiomyocytes after myocardial infarction. Blood 2004, 104:3581-3587

5. Minatoguchi S, Takemura G, Chen XH, Wang N, Uno Y, Koda M, Arai M, Misao Y, Lu C, Suzuki K, Goto K, Komada A, Takahashi T, Kosai K, Fujiwara T, Fujiwara H: Acceleration of the healing process and myocardial regeneration may be important as a mechanism of improvement of cardiac function and remodeling by postinfarction granulocyte colony-stimulating factor treatment. Circulation 2004, 109:2572-2580

6. Harada M, Qin Y, Takano H, Minamino T, Zou Y, Toko H, Ohtsuka M, Matsuura K, Sano M, Nishi J, Iwanaga K, Akazawa H, Kunieda T, Zhu W, Hasegawa H, Kunisada K, Nagai T, Nakaya H, Yamauchi-Takihara K, Komuro I: G-CSF prevents cardiac remodeling after myocardial infarction by activating the Jak-Stat pathway in cardiomyocytes. Nat Med 2005, 11:305-311

7. Li Y, Takemura G, Okada H, Miyata S, Esaki M, Maruyama R, Kanamori H, Li L, Ogino A, Misao Y, Khai NC, Mikami A, Minatoguchi S, Fujiwara T, Fujiwara H: Treatment with granulocyte colony-stimulating factor ameliorates chronic heart failure. Lab Invest 2006, 86:32-44

8. Lieschke GJ, Grail D, Hodgson G, Metcalf D, Stanley E, Cheers C, Fowler KJ, Basu S, Zhan YF, Dunn AR: Mice lacking granulocyte colony-stimulating factor have chronic neutropenia, granulocyte and macrophage progenitor cell deficiency, and impaired neutrophil mobilization. Blood 1994, 84:1737-1746

9. Committee for the Update of the Guide for the Care and Use of Laboratory Animals; National Research Council: Guide for the Care and Use of Laboratory Animals: Eighth Edition. Washington, DC, National Academies Press, 2011

10. Takeyama T, Takemura G, Kanamori H, Kawaguchi T, Ogino A Watanabe T, Morishita K, Tsujimoto A, Goto K, Maruyama R, Ushikoshi H, Kawasaki M, Yamada K, Nikami H, Fujiwara T, Fujiwara H, Minatoguchi S: Asialoerythropoietin, a nonerythropoietic derivative of erythropoietin, displays broad anti-heart failure activity. Circ Heart Fail 2012, 5:274-285 
11. Kanamori H, Takemura G, Goto $\mathrm{K}$, Tsujimoto A, Ogino A, Takeyama T, Kawaguchi T, Watanabe T, Morishita K, Kawasaki M, Mikami A, Fujiwara T, Fujiwara H, Seishima M, Minatoguchi S: Resveratrol reverses remodeling in hearts with large, old myocardial infarctions through enhanced autophagy-activating AMP kinase pathway. Am J Pathol 2013, 182:701-713

12. Presta LG, Chen H, O'Connor SJ, Chisholm V, Meng YG, Krummen L, Winkler M, Ferrara N: Humanization of an anti-vascular endothelial growth factor monoclonal antibody for the therapy of solid tumors and other disorders. Cancer Res 1997, 57:4593-4599

13. Los M, Roodhart JM, Voest EE: Target practice: lessons from phase III trials with bevacizumab and vatalanib in the treatment of advanced colorectal cancer. Oncologist 2007, 12:443-450

14. Kawaguchi T, Takemura G, Kanamori H, Takeyama T, Watanabe T, Morishita K, Ogino A, Tsujimoto A, Goto K, Maruyama R, Kawasaki M, Mikami A, Fujiwara T, Fujiwara H, Minatoguchi S: Prior starvation mitigates acute doxorubicin cardiotoxicity through restoration of autophagy in affected cardiomyocytes. Cardiovasc Res 2012, 96:456-465

15. Maekawa N, Wada H, Kanda T, Niwa T, Yamada Y, Saito K, Fujiwara H, Sekikawa K, Seishima M: Improved myocardial ischemia/reperfusion injury in mice lacking tumor necrosis factor-alpha. J Am Coll Cardiol 2002, 39:1229-1235

16. Li L, Okada H, Takemura G, Esaki M, Kobayashi H, Kanamori H, Kawamura I, Maruyama R, Fujiwara T, Fujiwara H, Tabata Y, Minatoguchi S: Sustained release of erythropoietin using biodegradable gelatin hydrogel microspheres persistently improves lower leg ischemia. J Am Coll Cardiol 2009, 53:2378-2388

17. Bussolino F, Wang JM, Defilippi P, Turrini F, Sanavio F, Edgell CJ, Aglietta M, Arese P, Mantovani A: Granulocyte- and granulocytemacrophage-colony stimulating factors induce human endothelial cells to migrate and proliferate. Nature 1989, 337:471-473

18. Powell TM, Paul JD, Hill JM, Thompson M, Benjamin M, Rodrigo M, McCoy JP, Read EJ, Khuu HM, Leitman SF, Finkel T, Cannon RO $3^{\text {rd }}$ : Granulocyte colony-stimulating factor mobilizes functional endothelial progenitor cells in patients with coronary artery disease. Arterioscler Thromb Vasc Biol 2005, 25:296-301

19. Silvestre JS, Smadja DM, Lévy BI: Postischemic revascularization: from cellular and molecular mechanisms to clinical applications. Physiol Rev 2013, 93:1743-1802

20. Ohki Y, Heissig B, Sato Y, Akiyama H, Zhu Z, Hicklin DJ, Shimada K, Ogawa H, Daida H, Hattori K, Ohsaka A: Granulocyte colony-stimulating factor promotes neovascularization by releasing vascular endothelial growth factor from neutrophils. FASEB J 2005, 19:2005-2007

21. Boesiger J, Tsai M, Maurer M, Yamaguchi M, Brown LF, Claffey KP, Dvorak HF, Galli SJ: Mast cells can secrete vascular permeability factor/vascular endothelial cell growth factor and exhibit enhanced release after immunoglobulin E-dependent upregulation of fc epsilon receptor I expression. J Exp Med 1998, 188:1135-1145

22. Shimoji K, Yuasa S, Onizuka T, Hattori F, Tanaka T, Hara M, Ohno Y, Chen H, Egasgira T, Seki T, Yae K, Koshimizu U, Ogawa S, Fukuda K: G-CSF promotes the proliferation of developing cardiomyocytes in vivo and in derivation from ESCs and iPSCs. Cell Stem Cell 2010, 6:227-237

23. Leung DW, Cachianes G, Kuang WJ, Goeddel DV, Ferrara N: Vascular endothelial growth factor is a secreted angiogenic mitogen. Science 1989, 246:1306-1309

24. Neufeld G, Cohen T, Gengrinovitch S, Poltorak Z: Vascular endothelial growth factor (VEGF) and its receptors. FASEB J 1999, 13: 9-22

25. Kaipainen A, Korhonen J, Mustonen T, van Hinsbergh VW, Fang GH, Dumont D, Breitman M, Alitalo K: Expression of the fms-like tyrosine kinase 4 gene becomes restricted to lymphatic endothelium during development. Proc Natl Acad Sci U S A 1995, 92:3566-3570

26. Okada H, Takemura G, Li Y, Ohno T, Li L, Maruyama R, Esaki M, Miyata S, Kanamori H, Ogino A, Nakagawa M, Minatoguchi S, Fujiwara T, Fujiwara H: Effect of a long-term treatment with a low-dose granulocyte colony-stimulating factor on post-infarction process in the heart. J Cell Mol Med 2008, 12:1272-1283

27. Shibuya M, Classon-Welsh L: Signal transduction by VEGF receptors in regulation of angiogenesis and lymphangiogenesis. Exp Cell Res 2006, 312:549-560

28. Al-Salam S, Hashmi S: Galectin-1 in early acute myocardial infarction. PLoS One 2014, 9:e86994

29. Chung J, Uchida E, Grammer TC, Blenis J: STAT3 serine phosphorylation by ERK-dependent and -independent pathways negatively modulates its tyrosine phosphorylation. Mol Cell Biol 1997, 17:6508-6516

30. Yin FC: Ventricular wall stress. Circ Res 1981, 49:829-842

31. Desmoulière A, Redard M, Darby I, Gabbiani G: Apoptosis mediates the decrease in cellularity during the transition between granulation tissue and scar. Am J Pathol 1995, 146:56-66

32. Takemura G, Ohno M, Hayakawa Y, Misao J, Kanoh M, Ohno A, Uno Y, Minatoguchi S, Fujiwara T, Fujiwara H: Role of apoptosis in the disappearance of infiltrated and proliferated interstitial cells after myocardial infarction. Circ Res 1998, 82:1130-1138

33. Hayakawa K, Takemura G, Kanoh M, Li Y, Koda M, Kawase Y, Maruyama R, Okada H, Minatoguchi S, Fujiwara T, Fujiwara H: Inhibition of granulation tissue cell apoptosis during the subacute stage of myocardial infarction improves cardiac remodeling and dysfunction at the chronic stage. Circulation 2003, 108:104-109

34. Li Y, Takemura G, Kosai K, Takahashi T, Okada H, Miyata S, Yuge K, Nagano S, Esaki M, Khai NC, Goto K, Mikami A, Maruyama R, Minatoguchi S, Fujiwara T, Fujiwara H: Critical roles for the Fas/Fas ligand system in postinfarction ventricular remodeling and heart failure. Circ Res 2004, 95:627-636

35. Kim CB, Braunwald E: Potential benefits of late reperfusion of infarcted myocardium: the open artery hypothesis. Circulation 1993, $88: 2426-2436$

36. Marroquin OC, Lamas GA: Beneficial effects of an open artery on left ventricular remodeling after myocardial infarction. Prog Cardiovasc Dis 2004, 42:471-483

37. Hochman JS, Choo H: Limitation of myocardial infarct expansion by reperfusion independent of myocardial salvage. Circulation 1987, 75: 299-306

38. Hale SL, Kloner RA: Left ventricular topographic alterations in the completely healed rat infarct caused by early and late coronary artery reperfusion. Am Heart J 1988, 116:1508-1513

39. Nakagawa M, Takemura G, Kanamori H, Goto K, Maruyama R, Tsujimoto A, Ohno T, Okada H, Ogino A, Esaki M, Miyata S, Li L, Ushikoshi H, Aoyama T, Kawasaki M, Nagashima K, Fujiwara T, Minatoguchi S, Fujiwara H: Mechanisms by which late coronary reperfusion mitigates postinfarction cardiac remodeling. Circ Res 2008, 103:98-106

40. Kloner RA, Hwang H: New insights into the open artery hypothesis. Circ Res 2008, 103:1-3

41. von Harsdorf R: "Fas-ten" your seat belt: anti-apoptotic treatment in heart failure takes off. Circ Res 2004, 95:554-556

42. Okada H, Takemura G, Kosai K, Tsujimoto A, Esaki M, Takahashi T, Nagano S, Kanamori H, Miyata S, Li Y, Ohno T, Maruyama R, Ogino A, Li L, Nakagawa M, Nagashima K, Fujiwara T, Fujiwara H, Minatoguchi S: Combined therapy with cardioprotective cytokine administration and antiapoptotic gene transfer in postinfarction heart failure. Am J Physiol Heart Circ Physiol 2009, 296:H616-H626 